\title{
TEATRO FILOSÓFICO: APRENDER E ENSINAR FILOSOFIA COM DELEUZE
}

\author{
Aldo Batista de Azevedo Júnior* \\ Marcos de Camargo von Zuben**
}

\begin{abstract}
Resumo: $\mathrm{O}$ artigo aborda o ensino e a aprendizagem de filosofia a partir da noção de criação de conceitos, conforme o entendimento de Deleuze. Para isso, discute o que significa criar conceitos em filosofia, associando essa concepção a uma nova imagem do pensamento que entende a criação de conceitos como o dizer do acontecimento, o sentido incorporal produzido pelo efeito do encontro dos corpos. Depois estabelece os vínculos entre o sentido e o acontecimento com uma nova imagem sobre ensinar e aprender filosofia e conclui com a figura do teatro para compreender esses vínculos.

Palavras-chave: Ensinar; Aprender; Criação de conceitos; Acontecimento; Deleuze.

Resumen: El artículo aborda la enseñanza y el aprendizaje de la filosofía desde la noción de creación de conceptos, tal como la comprensión de Deleuze. Para esto, discute lo que significa crear conceptos en filosofía, asociando esa concepción con una nueva imagen de pensamiento que comprende la creación de conceptos como el dicho del evento, el sentido incorpóreo producido por el efecto de la reunión de los cuerpos. Luego establece los vínculos entre significado y evento con una nueva imagen sobre la enseñanza y el aprendizaje de la filosofía y concluye con la figura del teatro para comprender estos vínculos.
\end{abstract}

Palabras claves: Enseñanza; Aprender; Creación de conceptos; Evento; Deleuze.

\section{Introdução}

O objetivo deste artigo é pensar o ensino e a aprendizagem filosófica como criação de conceitos, de acordo com Deleuze e Guattari (2010). Compor a ideia de ensino e aprendizagem a partir do que se entende por criação de conceitos é adentrar em uma nova imagem do pensamento, uma nova imagem do filosofar que supera a ideia de conceito como representação abstrata das coisas, pois o conceito diz o acontecimento $e$ não a essência ou a coisa. Assim, dizer o conceito não é dizer o significado das coisas, mas o sentido do encontro entre as coisas. Essa nova imagem do conceito em filosofia nos leva, portanto, a entendê-lo a partir do sentido-acontecimento, noções centrais para se pensar uma nova imagem do aprender $e$ do ensinar filosofia.

Como compreender o conceito enquanto sentido-acontecimento? Que implicações essa ideia de conceito tem para uma nova ideia de aprender e ensinar filosofia? São essas as perguntas que se pretende responder, ainda que de modo sumário, nas linhas a seguir. Para tanto, desenvolve-se a ideia de que o teatro é a melhor figura para dizer essa relação entre a noção de conceito como sentido-acontecimento e a ideia de aprender e ensinar filosofia. São conhecidas as várias referências de Deleuze (1992; 2015 ; 2018) quanto ao papel da noção de

\footnotetext{
"UERN/CAPES - aldusjunior@yahoo.com.br.

***UERN-zuben@uol.com.br.
}

AZEVEDO JÚNIOR, Aldo Batista de; ZUBEN, Marcos de Camargo von. Teatro filosófico: aprender e ensinar filosofia com Deleuze. Revista Sul-Americana de Filosofia e Educação. Número 34: nov. 2020 - abril 2021, p. 140-158. DOI: https://doi.org/10.26512/resafe.v2i34.35137 
teatro como o movimento do filosofar ${ }^{3}$, não o teatro da representação, mas o teatro da repetição e da diferença.

Esses temas educacionais deleuzianos têm despertado cada vez mais interesse no Brasil $^{4}$, e as questões a serem investigadas já receberam algumas respostas em estudos realizados $^{5}$. Não obstante a importância desses estudos, carece uma melhor articulação da noção de conceito como o dizer do acontecimento-sentido com as noções de aprender e ensinar, objetivo maior deste artigo.

Com apoio nos escritos de Deleuze e outros estudos, pretende-se em um primeiro momento estabelecer as relações entre criar conceitos e dizer o acontecimento-sentido, de modo a esclarecer melhor essa nova imagem do pensamento e a que se refere Deleuze quando diz que a filosofia é criação de conceitos. No segundo momento, discute-se a relação desse teatro-acontecimento com o teatro-aprendizagem e o teatro-ensino, procurando ver em que medida a noção de criação de conceitos lança luz sobre os conceitos de aprender e ensinar filosofia.

\section{O teatro dos encontros}

Uma questão tão antiga quanto a própria existência da filosofia é a sua definição: o que é filosofia? Muitas respostas foram dadas a tal questão. Deleuze e Guattari, filósofos franceses do século XX, também definiram essa questão na introdução de sua obra, O que é filosofia? (DELEUZE; GUAT-

\footnotetext{
3 Araya (2019) e Vasconcellos (2010) destacam o aspecto central da noção de teatro para a compreensão da filosofia de Deleuze.

${ }^{4}$ Cf. Dossiês sobre o tema nas revistas Educação e realidade (2002) e Educação e Sociedade (2005).

${ }^{5}$ Cf. Bianco (2003), La Salvia (2015; 2019), Macedo; Carvalho (2018), Gallo (2012).
}

TARI, 2010, p. 7-8): "Mas o que é isso que fiz toda a minha vida? [...] Simplesmente chegou a hora, para nós, de perguntar o que é a filosofia. [...] a filosofia é a arte de formar, de inventar, de fabricar conceitos". A filosofia tem a sua questão que lhe é própria: "A questão da filosofia é o ponto singular onde o conceito e a criação se remetem um ao outro". (DELEUZE; GUATTARI, 2010, p. 18). Sendo a filosofia essa atividade de construir, criar conceito, faz-se necessário esclarecer o que é um conceito. Eles nos alertam que essa questão da definição do conceito recebeu pouca importância dentro da tradição filosófica.

Os filósofos não se ocuparam o bas-
tante com a natureza do conceito
como realidade filosófica. Eles prefe-
riram considerá-lo como um conhe-
cimento ou uma representação da-
dos, que se explicam por faculdades
capazes de formá-lo (abstração ou
generalização) ou de utilizá-los (juí-
zo). Mas o conceito não é dado, está
por criar; não é formado, ele próprio
se põe a si mesmo, autoposição.
(DELEUZE; GUATTARI, 2010, p.
18. Grifos nossos).

É em uma linhagem de filósofos da tradição filosófica que remonta ao estoicismo, epicurismo e aos filósofos que beberam dessa fonte que Deleuze encontrará seus pressupostos para definir o conceito como algo que tem seu início a partir do exterior, em um encontro entre dois corpos produzindo efeitos que não são seres reais como os corpos, mas incorporais. "Não são substantivos ou adjetivos, mas verbos. Não são agentes nem pacientes, mas resultados de ações $e$

Número 34: nov. 2020 - abril 2021 
paixões, 'impassíveis' - impassíveis resultados". (DELEUZE, 2015, p. 7).

Esses verbos expressam algo que acontece aos corpos na sua relação uns com os outros, interpenetrando-se como no exemplo utilizado por Deleuze do verde da árvore onde há a penetração do verde na árvore, em uma única realidade, mas com duas existências reais: a árvore e o verde juntos. Não há acréscimo de existência real a nem uma dessas realidades porque elas são causa de suas próprias existências, mas há a produção de efeito, ou seja, algo acontece: o verdejar da árvore. Esse novo modo de ver as coisas, não a árvore verde, mas o fato do "verdejar da árvore" é o que se denomina acontecimento, aquilo que se passa entre duas realidades existentes, sem, no entanto, causar mudanças nas substâncias envolvidas. $\mathrm{O}$ acontecimento é um incorporal, não possui realidade própria, somente existe no encontro do verde com a árvore, no verdejar da árvore. (DELEUZE, 2015, p. 6-7).

Que lugar precisa ocupar essa noção de acontecimento no âmbito do desenvolvimento do pensamento? Qual a função dessa "realidade" no processo do pensar?

A grande inovação deleuziana é justamente propor a identificação do acontecimento como um sentido: um pensamento que tem por fundamento a lógica do sentido e não a lógica da representação conceitual. Utilizando-se da noção de exprimível elaborada por Bréhier ${ }^{6}$ na Teoria dos incorporais no estoicismo antigo, Deleuze (2015) propõe o sentido como o fundamento do discurso filosófico não em uma lógica proposicional de significação, mas em uma lógica de senti-

\footnotetext{
${ }^{6}$ Ver capítulo 2 - O incorporal na lógica e na teoria
} dos "exprimíveis", em Bréhier (2012). do como acontecimento, estabelecendo o sentido como a quarta dimensão da proposição, ao lado da designação, manifestação e significação. "Os Estoicos a descobriram com o acontecimento: o sentido é o expresso da proposição, este incorporal na superfície das coisas, entidade complexa irredutível, acontecimento puro que insiste ou subsiste na proposição". (DELEUZE, 2015, p. 20). "Esta dimensão última é chamada por Husserl expressão: ela se distingue da designação, da manifestação, da demonstração. O sentido é o expresso". (DELEUZE, 2015, p. 21). É nesse sentido que Deleuze contrapõe sua noção de conceito à noção de ideia de Platão, afirmando que a filosofia sempre trabalhou com conceitos, criou conceitos, mas

[...] eles foram usados para determinar o que uma coisa é (essência). Nós, ao contrário, nos interessamos pelas circunstâncias de uma coisa: em que casos, onde e quando, como, etc.? Para nós, o conceito deve dizer o acontecimento, e não mais a essência. Daí a possibilidade de introduzir procedimentos romanescos muito simples em filosofia. (DELEUZE, 1992, p. 37).

O cerne da diferença entre a lógica platônico-aristotélica e a lógica estoica, na qual Deleuze se inspira, é a concepção de semelhança e diferença que está na base dessas lógicas. Bréhier (2012, p. 20-21) esclarece que, para Platão e Aristóteles,

[...] o problema era explicar o permanente nos seres, o estável, aquilo que poderia oferecer um ponto de apoio sólido ao pensamento por conceitos. [...] O que chama a aten- 
ção em um ser é, primeiramente, o elemento pelo qual ele se assemelha aos outros seres e que permite classificá-lo. Mas outro ponto de vista consiste em considerar este ser por sua história e sua evolução, do seu surgimento até o seu desaparecimento. O ser será, portanto, considerado não como parte de uma unidade superior, mas como sendo a unidade e o centro de todas as partes que constituem sua substância e de todos os acontecimentos que constituem sua vida. Ele será o desdobramento no tempo e no espaço desta vida, com suas contínuas mudanças.

Nesse sentido, é fácil compreender que os corpos são os atores de sua própria existência não dependendo de uma causa exterior para existirem, mas somente de uma causa interna presente em si mesmos que se desdobra em uma existência própria. Também é nesse sentido que, para os estoicos, os corpos não podem ser alterados em sua essência por outros corpos, mas tão somente conviverem juntos fazendo surgir os efeitos de superfície chamados por Deleuze de acontecimentos: o verdejar da árvore, já que no mais profundo dos seres são conservadas as mesmas substâncias. Assim, o que é atribuído à árvore como "o verdejar da árvore", que é a ação do verde sobre a árvore, não é uma modificação da árvore, mas um modo de ser da árvore e, portanto, uma realidade que em si não existe: um acontecimento ${ }^{7}$.

É nessa lógica de sentido que Deleuze estabelece o conceito como sendo um incorporal e não uma essência, uma ideia platônica, porque ele diz respeito ao acontecimento. "O conceito é um incorporal, embora

\footnotetext{
${ }^{7}$ Para maior compreensão, ver Lógica do sentido (DELEUSE, 2015, p. 11-23).
}

se encarne ou se efetue nos corpos [...]. Não tem coordenadas espaçotemporais, mas apenas ordenadas intensivas [...]. O conceito diz o acontecimento, não a essência ou a coisa". (DELEUZE; GUATTARI, 2010, p. 29). O conceito não é da natureza da representação, mas da natureza do acontecimento. Isso porque o conceito, embora seja expressado em uma proposição lógica, nos termos da proposição, ele não se confunde com esses termos, é exterior a eles, mas insiste, subsiste somente neles como expresso.

Inseparavelmente o sentido é o exprimível ou o expresso da proposição e o atributo do estado de coisas. Ele volta uma face para as coisas, uma face para as proposições. [...]. É neste sentido que é um "acontecimento": com a condição de não confundir o acontecimento com sua efetuação espaçotemporal em um estado de coisas. Não perguntaremos, pois, qual é o sentido de um acontecimento: o acontecimento é o próprio sentido. $\mathrm{O}$ acontecimento pertence essencialmente à linguagem, ele mesmo mantém uma relação essencial com a linguagem; mas a linguagem é o que se diz das coisas. (DELEUZE, 2015, p. 23).

O conceito mantém, então, esse vínculo com as realidades existentes, mas não existe sem elas, como essências, antes insiste nelas como "o verdejar da árvore": corpo e linguagem.

Essa problemática da expressão é retomada por Deleuze nos seus estudos sobre Espinosa, mais especificamente em Espinosa e o problema da expressão (2017). No Curso sobre Espinosa (1978), na aula do dia 24 de janeiro de 1978, Deleuze explica, a partir do pensamento de Espinosa, como este en- 
tende o processo de criação das ideias ${ }^{8}:$ a ideia-afecção, a ideia-noção e a ideiaessência (DELEUZE, 1978). O primeiro tipo de ideia, a ideia-afecção, é formado a partir da afecção (affectio) que é o resultado da mistura de dois corpos que acontece em um encontro qualquer, gerando um afeto (affectus) que corresponde a uma variação, um sentimento de alegria (aumento da potência de agir) ou de tristeza (diminuição da potência de agir). A afecção "[...] é uma mistura de dois corpos, um corpo que se diz agir sobre outro, e um corpo que recolhe o traço do primeiro. Toda mistura de corpos será chamada de afecção". (DELEUZE, 1978). A afecção é proporcionada pelo encontro (occursus) - o encontro que não se pode controlar. Viver ao acaso dos encontros é viver tendo por base as ideias-afecções. A ideiaafecção é o que Espinosa chama de ideia inadequada e corresponde ao primeiro gênero de conhecimento, o mais baixo porque só conhece as coisas pelos seus efeitos (DELEUZE, 1978.). O afeto (affectus) é

Todo modo de pensamento enquanto não representativo [...]. Uma volição, uma vontade, implica, a rigor, que eu queira alguma coisa; o que eu quero, isto é objeto de representação, o que eu quero é dado numa ideia, mas o fato de querer não é uma ideia, é um afeto, porque é um modo de pensamento não representativo. (DELEUZE, 1978. Grifos nossos).

\footnotetext{
${ }^{8}$ De maneira mais profunda e detalhada esse tema é discorrido em Espinosa e o problema da expressão, no capítulo XIV, intitulado Que pode um corpo? (DELEUZE, 2017, p. 239-257).
}

Assim, o que é primeiro na ordem do pensamento é a afecção que faz surgir ideias-afecções e desencadeia variações afetivas (affectus) de alegria ou tristeza. O afeto se diferencia da ideia porque ele é um modo de pensamento que não representa nada, sendo caracterizado por Deleuze, na sua leitura de Espinosa, como uma variação de potência de agir (alegre ou triste) que se processa no corpo-espírito. A ideia, por sua vez, é um modo de pensamento representativo já que ela estabelece uma relação entre a ideia e o objeto por ela representado. Mas, embora o afeto (afecctus) mantenha uma diferença de natureza em relação à ideia, necessariamente ele pressupõe uma ideia do ponto de visto cronológico e lógico porque quem deseja (afeto), deseja algo (objeto representado pela ideia). (DELEUZE, 1978).

Esse primeiro nível de conhecimento, as ideias-afecções, corresponde ao senso comum, sem criação filosófica ou mesmo científica e artística: são formas de conhecimento no nível inicial, portanto, o nível mais baixo de compreensão. Todas as pessoas chegam a esse nível de pensamento, explica Deleuze. Estamos, pois, por natureza, sujeitos a esse tipo de conhecimento: é o nível das opiniões.

Há um segundo tipo de ideia, as ideias-noções que correspondem ao pensamento filosófico. Como elas são geradas? Deleuze (1978) explica que essas ideias são geradas somente pelo afeto alegre porque esse afeto produz um aumento da potência de agir, chamado autoafecção ou afeto ativo que nos possibilita sair do domínio das paixões, que consiste em passividade, e entrar no domínio das ações que seria uma atividade criativa no processo do pensar. $\mathrm{O}$ que 
permite alcançar essa forma de pensar é o conhecimento das relações de composição estabelecidas pelos corpos, afetados de alegria ou de tristeza, ou seja:

As ideias-noções já não dizem respeito ao efeito de um outro corpo sobre o meu, é uma ideia que concerne e que tem por objeto a conveniência ou a inconveniência das relações características entre dois corpos. [...] A ideia-noção eleva-se à compreensão de causa, a saber: se a mistura produz este ou aquele efeito, é em virtude de natureza da relação entre os corpos considerados e da maneira pela qual a relação de um corpo se compõe com a relação do outro corpo. Sempre existe composição de relações. Uma ideia-noção é forçosamente adequada porque é um conhecimento pelas causas. (DELEUZE, 1978).

As ideias-noções são geradas na experiência vivida pela alegria já que somente o afeto alegre pode possibilitar uma relação de composição de corpos fazendo nascer uma noção comum a esses corpos que se convém.

Há um apelo evidente a uma maneira de perceber, e bem mais, a uma maneira de viver. É como se os afetos de alegria fossem um trampolim, eles fazem vocês passarem através de alguma coisa pela qual jamais poderiam passar se só existisse tristeza. Eles nos solicitam a formar a ideia do que é comum ao corpo que afeta e ao corpo que é afetado. Isso pode fracassar, mas pode ter sucesso e tornar-me inteligente. (DELEUZE, 1978).
Assim procedendo, de noção comum em noção comum se constrói uma filosofia, um pensamento novo gerado no encontro, pela alegria, na relação de composição de corpos: as ideias-noções.

Spinoza propõe o seguinte: ao invés de fazer o somatório de nossas tristezas, tomar uma alegria como um ponto de partida local, à condição que sintamos que ela nos concerne verdadeiramente. Em cima disso forma-se a noção comum, em cima disso tenta-se ganhar localmente, estender essa alegria. É um trabalho para toda a vida. [...] Isso se torna não mais uma variação contínua, mas uma curva ascendente. Vocês partem das paixões alegres, aumento da potência de agir, vocês se servem delas para formar noções comum viventes, e vocês voltam a descer em direção à tristeza, desta vez com noções comuns que vocês formam para compreender em que determinado corpo não convém com o seu, em que determinada alma não convém com a sua. Nesse momento, vocês já podem dizer que estão na ideia adequada porque, com efeito, vocês entraram no conhecimento das causas. Vocês já podem dizer que estão na filosofia. (DELEUZE, 1978).

Só posso conhecer o que a constituição do meu corpo-espírito me permite conhecer. Isso porque as condições de conhecimento são dadas pela minha constituição corpo-espírito que define as ideias que se compõem na relação afecção-afeto (affectioaffectus). E essa constituição varia ao longo de uma vida, mudando constantemente, não sendo a mesma na infância e na velhice, por exemplo. 
[...] o que pode um corpo? De que afetos é ele capaz? Os afetos são devires: ora eles nos enfraquecem, quando diminuem nossa potência de agir e decompõem nossas relações (tristeza), ora nos tornam mais fortes, quando aumentam nossa potência e nos fazem entrar em um indivíduo mais vasto ou superior (alegria). Espinoza está sempre se surpreendendo com o corpo. Ele não se surpreende de ter um corpo, mas com o que o corpo pode. Os corpos não se definem por seu gênero ou sua espécie, por seus órgãos e suas funções, mas por aquilo que podem, pelos afetos dos quais são capazes, tanto na paixão quanto na ação. (DELEUZE; PARNET, 1998, p. 49).

Nesse sentido, Deleuze conclui que toda a nossa capacidade de criação no pensamento está relacionada com uma ação prática: movimento do devir que é nossa capacidade de afetar e ser afetado. E, daí, toda sua admiração por Espinosa sintetizar todo o seu pensamento numa Ética: uma prática de vida. É na realização da vida, no seu movimento de expressão que também o ser humano em seus modos expressa suas ideias na sua forma de viver. Há, nos signos ou afecções, sempre uma relação de encontro e composição/decomposição (afecçãoafeto) porque ele é sempre o efeito de um encontro entre dois corpos, em uma imanência: o caçador assume uma relação de animalidade, torna-se animal, quando reconhece o signo emitido por um animal. (DELEUZE, 2008). O que acontece é uma relação afecção-afeto para que haja essa relação de identificação (as pegadas deixadas indicam a presença do animal naquele território). Logo em seguida, Deleuze indica essa passagem iluminadora: "O escritor está à espreita, o filósofo está à espreita. É evidente que estamos à espreita". (DELEUZE, 2008). É necessário estar à espreita, atento ao acontecimento que se passa, aos outros, ao mundo. Deleuze tinha o hábito de sair aos sábados e domingos para ir ao cinema, exposições etc. no intuito de estabelecer encontros, não com pessoas, mas com qualquer realidade, uma música, um filme etc. (DELEUZE, 1988). Há aqui uma compreensão de estar sempre atento ao que se passa, às coisas. É a abertura, a atenção, caçar os rastros, os signos nos encontros. O aprendizado se dá no estado de "estar à espreita", estar atento, portanto. É nesse sentido que Deleuze (2003, p. 26) diz: "Confundimos o significado com o ser ou o objeto que ele designa. Passamos ao largo dos mais belos encontros, nos esquivando dos imperativos que deles emanam: ao aprofundamento dos encontros, preferimos a facilidade das recognições".

\section{O teatro filosófico}

$\mathrm{Na}$ introdução de Diferença e Repetição, Deleuze analisa o movimento do pensamento como um teatro em contraposição à representação e dá como exemplos de autores que souberam usar da técnica de produção conceitual teatral Nietzsche e Kierkegaard, porque elaboraram formas próprias de fazer filosofia por meio de novas formas de linguagem filosófica, uma linguagem filosófica cênica, teatral.

Kierkegaard e Nietzsche estão entre os que trazem à filosofia novos meios de expressão. A propósito deles, fala-se de bom grado em ultrapassa- 
gem da filosofia. Ora, o que está em questão nas obras deles é o movimento. [...] Não lhes basta, pois, propor uma nova representação do movimento; a representação já é mediação. Ao contrário, trata-se de produzir, na obra, um movimento capaz de comover uma obra, sem interposição; de substituir representações mediatas por signos diretos; de inventar vibrações, rotações, giros, gravitações, danças ou saltos que atinjam diretamente o espírito. Esta é uma ideia de homem de teatro, uma ideia de encenador - avançada para seu tempo. [...] É neste sentido que algo completamente novo começa com Kierkegaard e Nietzsche. [...] Eles inventam, na filosofia, um incrível equivalente do teatro, fundando, com isso, o teatro do futuro $e$, ao mesmo tempo, uma nova filosofia. (DELEUZE, 2018, p. 26).

Essa concepção de teatro como uma nova forma avançada para se fazer filosofia está em sintonia com a concepção deleuziana de fazer filosofia em diálogo com outras formas de conhecimento, como as ciências e as artes, a cada uma cabendo suas especificidades próprias, sendo a da filosofia a criação de conceitos. O pensamento que é ativado por forças externas, pelo caos que são as indeterminações, o que aparece e desaparece sem possibilitar conhecimento, que $\mathrm{o}$ obrigam a movimentos de pensamento que se desdobram em filosofia, ciências e artes: a filosofia cria conceitos, a ciência cria funções $e$ as artes criam perfectos e afectos. A ciência cria funções aplicadas a regiões do caos. As artes criam composições estéticas (perfectos e afectos) para também dar sentido a essas porções caóticas. A filosofia pensa por conceitos esse mesmo caos na sua infinitude: ela reinicia em cada singularidade, em cada afeto um novo conceito. Criação de conceito que se faz a partir da experiência vivida, por meio do signo.

O teatro da repetição opõe-se ao te-
atro da representação, como o mo-
vimento opõe-se ao conceito e à re-
presentação que o relaciona ao con-
ceito. No teatro da repetição, expe-
rimentamos forças puras, traçados
dinâmicos no espaço que, sem in-
termediários, agem sobre o espírito,
unindo-o diretamente à natureza e à
história, experimentamos numa lin-
guagem que fala antes das palavras,
gestos que se elaboram antes dos
corpos organizados, máscaras antes
dos rostos, espectros e fantasmas an-
tes das personagens - todo o apare-
lho da repetição como "potência ter-
rível". (DELEUZE, 1998, p. 28).

Há nesse Theatrum Philosophicum ${ }^{9}$, utilizando uma expressão de Foucault, todo um movimento do conhecimento em ligação essencial com a vida pulsante imanente como o palco desse grande teatro filosófico com seus planos de imanências e personagens conceituais. Nesse teatro filosófico, pelo método de dramatização, o conceito encarna-se ou atualiza-se nesse movimento no pensamento. Vê-se que os personagens conceituais são responsáveis pelos conceitos criados porque são seus portadores, são eles que parem os conceitos a partir do invólucro dos personagens conceituais que é o filósofo, nesse caso, Deleuze. Entende-se, assim, ex-

\footnotetext{
9 Theatrum Philosophicum é o título que Foucault (2005, p. 230-254) dá a seu artigo sobre a prática filosófica de Deleuze quando analisa Diferença e Repetição e Lógica do Sentido em artigo publicado na revista francesa Critique.
} 
pressões como o Espinosa de Deleuze, o Bergson de Deleuze, entre outras.

O personagem conceitual não é o representante do filosófico, é mesmo o contrário: o filósofo é somente o invólucro de seu principal personagem conceitual e de todos os outros que são os intercessores, os verdadeiros sujeitos de sua filosofia. Os personagens conceituais são os "heterônimos" do filósofo, e o nome do filósofo, o simples pseudônimo de seus personagens. Eu não sou mais eu, mas uma aptidão do pensamento para se ver e se desenvolver através de um plano que me atravessa em vários lugares. $\mathrm{O}$ personagem conceitual nada tem a ver com uma personificação abstrata, um símbolo ou uma alegoria, pois ele vive, ele insiste. O filósofo é a idiossincrasia de seus personagens conceituais. E o destino do filósofo é de transformarse em seu ou seus personagens conceituais, ao mesmo tempo que estes personagens se tornam, eles mesmos, coisas diferentes do que são historicamente, mitologicamente ou comumente (o Sócrates de Platão, o Dioniso de Nietzsche, o Idiota de Cusa). (DELEUZE, 2010, p. 78-79).

É possível fazer referência, nesse sentido, aos pseudônimos da obra de Kierkegaard para ajudar a ilustrar melhor esse conceito deleuziano de personagem conceitual. Deleuze (2018) fala da sua admiração pela forma teatral kierkegaardiana e nietzschiana de se fazer filosofia. Kierkegaard, "[...] um pensador que vive o problema das máscaras, que experimenta este vazio interior próprio da máscara e que procura supri-lo, preenchê-lo, mesmo que seja com o 'absolutamente diferente' [...] a ideia de um teatro do humor e da fé". (DELEUZE, 2018, p. 26); Nietzsche, também, trata "[...] de preencher o vazio interior da máscara num espaço cênico: multiplicando as máscaras superpostas, inscrevendo a onipresença de Dioniso nesta superposição, colocando aí o infinito do movimento real como a diferença absoluta na repetição do eterno retorno". (DELEUZE, 2018, p. 27). O personagem conceitual assume seu plano de imanência para gerar um conceito. Integrando esse teatro de criação das ideias, com o método de dramatização o drama conceitual proposto por Deleuze tem o plano de imanência como palco, e na cena, em evidência, os personagens conceituais, atores na criação conceitual.

$\mathrm{Na}$ enunciação filosófica, não se faz algo dizendo-o, mas faz-se o movimento pensando-o, por intermédio de um personagem conceitual. Assim, os personagens conceituais são verdadeiros agentes de enunciação. Quem é Eu? é sempre uma terceira pessoa. (DELEUZE; GUATTARI, 2010, p. 79).

Agentes de enunciação é a definiçãochave para entender a ação do personagem conceitual na criação do conceito: é esse personagem o portador, a potência do conceito, que dá forma ao conceito dentro da problematização desse conceito no plano de imanência, verdadeiro articulador do sentido em elaboração; não como sujeito que examina um objeto, mas sim como um sujeito que é formado junto com o objeto, ambos sendo gerados no mesmo lance.

Os personagens conceituais são pensadores, unicamente pensadores, e seus traços personalísticos se juntam 
estreitamente aos traços diagramáticos do pensamento $e$ aos traços intensivos dos conceitos. Tal ou tal personagem conceitual pensa em nós, e talvez não nos preexistia. [...] Gago, amigo, juiz não perdem sua existência concreta, ao contrário, assumem uma nova existência, como condições interiores do pensamento para seu exercício real, com tal ou tal personagem conceitual. [...] Não são mais determinações empíricas, psicológicas e sociais, ainda menos abstrações, mas intercessores, cristais ou germes do pensamento. (DELEUZE; GUATTARI, 2010, p. 84).

Exemplo dessa compreensão da construção conceitual como teatro filosófico é o conceito de Ideia. Na interpretação de Deleuze, o conceito de Ideia em Platão não corresponde a uma essência, uma substância, mas tão somente a um modelo de medida por meio do qual todas as coisas serão comparadas, sendo, pois, não uma essência com existência própria, mas tão somente uma construção de significação, um discurso lógico de sentido, ou uma lógica de sentido, não uma platônico-aristotélica. Isso explica a compreensão de Deleuze de que um conceito sempre responde a um problema, ele desempenha um papel particular: ser a resposta a um problema específico. Nesse caso, a questão de Platão diz respeito ao problema dos pretendentes. A Ideia de Platão é um conceito, a solução para o problema dos pretendentes e, por isso, é compreendida como um modelo elaborado para servir de modelo, de medida para selecionar aquele que mais se aproxima desse mesmo modelo.

Acho que o que ele chama de "Ideia" é uma coisa que não seria outra coisa. Ou seja, que seria apenas o que ela é. [...]. É o que Platão quis dizer quando disse: "Só a Justiça é justa". Porque só a Justiça não é outra coisa além de justa. [...]. Ele não diz isso por acaso, não criou este conceito de Ideia por acaso. Ele se encontra em uma determinada situação em que, aconteça o que acontecer, em uma situação muito concreta, o que quer que aconteça ou o que quer que seja dado, há pretendentes. Há pessoas que dizem: "Para tal coisa, eu sou o melhor". [...]. E é a Ideia, a coisa em seu estado puro, que permitirá esta seleção e selecionará aquele que mais se aproxima. (DELEUZE, 2008. Grifos do autor).

Um problema é sempre um problema real porque nasceu de um encontro, não existe problema abstrato. A solução desse problema implica todo um movimento, um processo do pensamento em busca de uma resposta, um conceito. Desse ponto de vista, o pensamento não é uma inclinação natural, não é uma disposição da natureza humana porque ele necessita ser provocado, violentado pelo signo, perturbado pelo exterior. $\mathrm{O}$ pensamento, então, necessariamente está ligado à experiência, não pode existir sem ela porque dela deriva como início, tem lá sua gênese, como processo.

A interrogação não é senão a sombra do problema projetado ou antes reconstituído a partir das proposições empíricas; mas o problema em si mesmo é a realidade de elemento genético, o tema complexo que não se deixa reduzir a nenhuma tese de proposição. É uma só e mesma ilusão que, sob um aspecto empírico, decalca o problema nas proposições que lhe servem de "respostas" e que, 
sob um aspecto filosófico e científico, define o problema pela forma de possibilidade das proposições "correspondentes". [...] Jamais o problema se parece às proposições que ele subsume, nem às relações que engendra na proposição: ele não é proposicional, embora exista fora das proposições que o exprimem. (DELEUZE, 2015, p. 126-127).

Essa gênese do problema se dá a partir de um plano de imanência. Conceito bastante complexo, o plano de imanência é o território do conceito: não há conceito sem plano de imanência porque ele oferece as coordenadas ou diagramas para a instauração do problema e do conceito, imbricados um no outro. O plano de imanência é o solo, as coordenadas, de onde vai brotar o conceito. Ele é, portanto, pré-filosófico.

Numa palavra, os primeiros filósofos são aqueles que instauram um plano de imanência como um crivo estendido sobre o caos. Eles se opõem, neste sentido, aos Sábios, que são personagens da religião, sacerdotes, porque concebem a instauração de uma ordem sempre transcendente, imposta de fora por um grande déspota ou por um deus superior aos outros, [...]. Há religião cada vez que há transcendência, Ser vertical, Estado imperial no céu ou sobre a terra, e há Filosofia cada vez que houver imanência, [...]. Resta que os primeiros filósofos traçam um plano, que movimentos ilimitados não cessam de percorrer, sobre duas faces, das quais uma é determinável como Physis, na medida em que dá uma matéria ao Ser, e a outra como Noûs, enquanto dá uma imagem ao pensamento. [...]. O filósofo opera um vasto sequestro da sabedoria, ele a põe a serviço da imanência pura. Ele substitui a genealogia por uma geologia. (DELEUZE; GUATTARI, 2010, p. 54-55).

Inspirado no conceito de imanência em Espinosa, o plano de imanência constitui, pode-se dizer, a particularidade de cada conceito e o problema elaborado a partir de um determinado plano. Assim, por exemplo, o conceito de Ideia em Platão surge, na visão de Deleuze, como problema de selecionar pretendentes rivais:

Eu digo: um filósofo cria conceitos. Por exemplo, a Ideia, a coisa enquanto pura [...] há uma série de rivais que pretendem esta coisa [político como pastor de homens], são pretendentes [...] como descobrir em meio aos pretendentes qual deles é o bom. E é a Ideia, a coisa em seu estado puro, que permitirá esta seleção e selecionará aquele que mais se aproxima. [...] Por que é que foi Platão quem inventou este problema? $\mathrm{O}$ problema é como selecionar os pretendentes e o conceito... a filosofia é isso: problema e conceito. O conceito é a Ideia, que deveria dar os meios para selecionar os pretendentes. Não importa como. Por que este problema, este conceito, se formou em um meio grego? (DELEUZE, 2008).

Assim, têm-se o problema e o conceito relacionado com o problema. Mas qual o motivo dessa configuração do problema e do conceito? É que eles estão imbricados em 
um determinado plano de imanência: o mundo grego e sua configuração política da democracia ateniense.

É que isso começa com os gregos, é um problema tipicamente grego, é problema da cidade, e da cidade democrática, mesmo se Platão não aceita isso. [...] É uma cidade democrática que, por exemplo, uma magistratura é objeto de pretensões. Há pretendentes, pretendo determinada função. [...] É uma civilização... onde o enfrentamento dos rivais aparece sempre, por isso eles inventam a ginástica, inventam os Jogos Olímpicos. [...] Haverá sempre pretendentes, a luta de Platão contra os sofistas. Segundo ele, os sofistas são pretendentes a algo a que não têm direito. $\mathrm{O}$ que vai definir o direito ou o não direito de um pretendente? (DELEUZE, 2008).

A partir desse exemplo, pode-se compreender como a prática filosófica é algo muito vivo, pulsante, ligado a problemas da vida concreta. Nesse sentido, Deleuze também indica a História da Filosofia como um lugar de encontros importantes que levam a uma aprendizagem filosófica. A História da Filosofia pode ser um lugar aonde se vai em busca de vida, nos encontros filosóficos com os filósofos e seus problemas. Nela, Deleuze encontrou filósofos da tradição os quais chamou intercessores: Epicuro, Lucrécio, Espinosa, Leibniz, Hume, Bergson, Kierkegaard, Nietzsche, entre outros. Todos lhe ajudaram a construir novos conceitos ou mesmo reformular um determinado conceito.

Assim, para Deleuze, a História da Filosofia não deve ser o agente repressor do pensamento, principalmente, para aqueles que estão iniciando seu movimento no pensamento filosófico, na companhia dos filósofos. Ela deve ser algo muito concreto e que tenha vida e não tão somente um desfile de ideias sedimentadas ao longo da história do pensamento filosófico humano porque ao entender "[...] que a Filosofia é abstrata, a história da Filosofia passa a ser abstrata em dobro, já que ela nem consiste mais em falar de ideias abstratas, mas em formar ideias abstratas a partir de ideias abstratas". (DELEUZE, 2008). A forma filosófica de trabalhar a História da Filosofia se constitui em identificar à qual questão ou problema o conceito criado por determinado filósofo está respondendo, e é justamente nesse processo de busca de compreensão que a filosofia se torna viva: um filosofar. De qualquer forma, existe nessa compreensão um processo de criação, porque se levantam questões a partir do texto de um autor estudado que ele próprio, o autor, não viu ou mesmo não quis responder e que podem constituir novas questões a partir das questões formuladas.

Fazer história da Filosofia é um longo aprendizado, em que se aprende, em que se é aprendiz, nesse duplo campo: a constituição dos problemas, a criação dos conceitos. O que é que mata, o que faz com que o pensamento possa ser idiota, débil, etc.? As pessoas falam, mas nunca se sabe de que problema elas falam. [...]. Se você não tiver nem conceito nem problemas, você fica na besteira, não faz filosofia. Isso mostra o quanto a filosofia é divertida, e a história da filosofia, já que é isso fazer história da filosofia! Não é muito diferente do que tem de fazer quando 
está em frente a um quadro ou uma obra musical. (DELEUZE, 2008).

Sendo essa prática de criar conceitos uma atividade própria do filósofo, isso não implica, segundo Deleuze, ser o filósofo um especialista, um entendido ou um erudito no assunto, mas pode ser visto como alguém que pratica uma atividade específica do pensamento, que é criar conceitos, assim como são atividades específicas música ou pintura. Logo, a História da Filosofia também pode ser como um teatro da história do pensamento vivo onde aqueles que souberam elaborar suas questões filosóficas o fizeram a partir do movimento da vida concreta e não de uma vida abstrata representacional porque seus problemas eram concretos e exigiam uma resposta concreta: o pensamento em constante movimento de constituição.

\section{Ensinar $e$ aprender filosofia}

Considerando o exposto no desenvolvimento deste artigo, expomos a seguinte questão: partindo de uma concepção de prática filosófica como criação de conceitos, tendo por base um movimento do teatro filosófico, como pensar uma prática de ensino de filosofia em sala de aula ou, em outros termos, como conceber a aprendizagem e o ensino de filosofia?

Muito embora Deleuze nunca tenha escrito um livro sobre como ensinar filosofia ou mesmo sobre como ser professor de filosofia em sala de aula, em sua obra, princi- palmente nas entrevistas que concedeu, é possível encontrar passagens nas quais ele fez alusão ao modo como ensinou e, assim, a partir daí pode-se construir um retrato sobre a prática de ensino de filosofia de Deleuze.

Para Deleuze, há uma possibilidade de se controlar o momento do ensino, até mesmo preparado de maneira a prever todos os passos a serem seguidos, como em um ensaio. Por outro lado, há uma impossibilidade de se controlar a aprendizagem, o que se aprende, como normalmente a compreendem as teorias pedagógicas modernas que formulam um verdadeiro arsenal de métodos de ensino-aprendizagem, cada um proclamando sua eficácia e produtividade.

Quando estudante, talvez no início de todo o seu processo de despertar para a vida de estudos, Deleuze (2008) relata o encontro estabelecido entre ele e Pierre Halbwachs, um professor do ginasial, em Deauville, onde Deleuze estudou por um ano, entre 1939 e 1940 , e em como o encontro com esse professor o despertou para o mundo da literatura, já que o próprio Deleuze diz que não tinha interesse pelos estudos e era um péssimo aluno na escola; seu único interesse era uma coleção de selos. Então, a experiência da convivência com esse professor o transformou. No Liceu Carnot onde estudava, em 1943, Deleuze fala do seu encontro com a filosofia por meio do seu professor de filosofia, Viale, que sempre o acompanhava na volta para casa, oportunidade na qual conversavam muito. Destaca seu encontro com os conceitos, o que o marcaria pelo resto da vida: "[...] a descoberta de um personagem de ficção. [...]. Quando eu aprendi o que Platão chamava de 'ideia', me parecia ter 
vida! Era animado! Eu sabia que era isso; que, para mim, era isso". (DELEUZE, 2008. Grifo do autor).

Nesse processo de aprendizagem, no encontro com esses signos emitidos por seus professores: Halbwachs, de literatura, e Viale, de filosofia, Deleuze se torna um aluno entusiasmado e sem mais problemas nos estudos: "Era bom em Letras. Até mesmo em Latim, eu era bom. Eu era um bom aluno. Em Filosofia, um ótimo aluno". (DELEUZE, 2008). Na visão de Deleuze, foram esses professores e seus signos que o despertaram para o mundo do conhecimento. $\mathrm{O}$ professor, em sala de aula, pode emitir signos, mas esses signos só podem ser interpretados pelo aluno, da sua maneira e do seu jeito, totalmente fora do controle do professor. A aprendizagem terá seu momento apropriado, mas não se sabe quando será ou mesmo se isso se dará de acordo com o planejado.

Nunca se sabe como uma pessoa aprende; mas, de qualquer forma que aprenda, é sempre por intermédio de signos, perdendo tempo, e não pela assimilação de conteúdos objetivos. [...]. Nunca aprendemos alguma coisa nos dicionários que nossos professores e nossos pais nos emprestam. O signo implica em si a heterogeneidade como relação. Nunca se aprende fazendo como alguém, mas fazendo com alguém, que não tem relação de semelhança com o que se aprende. (DELEUZE, 2003, p. 21. Grifos nossos).

Assim, aprender é um exercício de paciência e perseverança, que exige tempo. Esse seria um dos paradoxos de nossos tempos governados pela mentalidade do tempo acelerado. A filosofia, no entanto, exige tempo, desaceleração, solidão, na experiência dos encontros.

Aprender diz respeito essencialmente aos signos. Os signos são objeto de um aprendizado temporal, não de um saber abstrato. Aprender é, de início, considerar uma matéria, um objeto, um ser, como se emitissem signos a serem decifrados, interpretados. Não existe aprendiz que não seja "egiptólogo" de alguma coisa. Alguém só se torna marceneiro tornando-se sensível aos signos da madeira, e médico tornando-se sensível aos signos da doença. A vocação é sempre uma predestinação com relação a signos. Tudo que nos ensina alguma coisa emite signos, todo ato de aprender é uma interpretação de signos ou de hieróglifos. (DELEUZE, 1992, p. 4. Grifos nossos).

A pergunta que se faz, então, é: como ensinar filosofia em sala de aula, já que não se pode controlar o processo de aprendizagem, o que se aprende, que se faz no encontro com signos, mas é inconsciente? "[...] 'aprender' passa sempre pelo inconsciente, dá-se sempre no inconsciente, estabelecendo, entre a natureza e o espírito, o liame de uma cumplicidade profunda". (DELEUZE, 2018, p. 222. Grifo do autor).

Deleuze sempre fez as preparações de suas aulas de forma meticulosa, chamando mesmo essas preparações de ensaios, como em uma peça teatral, porque, para ele, sempre haveria encontros que causariam mudanças em alguém. Só não se sabe quando, onde, nem em quantos essa variação (afecto = bom encontro) aconteceria. 
A maneira de Deleuze preparar as aulas objetivava o "como" deveria fazer para que pudesse possibilitar o encontro entre a filosofia e os seus alunos, por meio do encontro do fazer filosofia do próprio Deleuze. Continuamos aqui com a lógica do acontecimento: o que pode acontecer quando alguém encontra a filosofia, no filosofar? Que efeito as questões trabalhadas pela filosofia produzem, na companhia dos filósofos, dos colegas e do professor de filosofia com sua prática? Que questões podem ser elaboradas? É o que veremos a seguir.

Deleuze desde "[...] seu primeiro ano de ensino" ${ }^{10}$, ele é um 'fantástico despertador', nas palavras de seu aluno Michel Marié":

Pela mobilidade e leveza de seu pensamento, pela aparente facilidade de seu ensino, pelo interesse que tinha pelas coisas da vida (o esporte, a roupa, a comida, a história das técnicas...), [...]. Com ele, a filosofia não era essa disciplina rígida que eu temia. Era o encontro, a fusão entre, de um lado, um aparelho conceitual, uma cultura com suas linguagens, suas técnicas de aprendizagem, suas explicações e seus encadeamentos, que se aprende em contato com gerações de pensadores, $e$, de outro lado, uma espécie de impulso secreto, de disposição do espírito a apreender, a conceber as coisas mais simples, as mais cotidianas $e$ as mais fundamentais da existência. (DOSSE, 2010, p. 91).

10 Deleuze foi professor do Liceu, em Amiens, de 1948 a 1952. O Liceu, na França, nessa época corresponderia, guardadas as devidas diferenças, ao Ensino Médio dos dias atuais, no Brasil.
É notório o movimento que Deleuze realiza, partindo da vida concreta dos alunos, direcionando o pensamento para pensar a vida cotidiana, as coisas mais simples $e$ a partir daí trilhar um caminho em busca do pensamento filosófico; a sua preocupação de tornar a filosofia algo vivo, uma verdadeira prática de vida e não tão somente um amontoado de informações. Partindo de problemas vivenciados pelos alunos no dia a dia, Deleuze busca os conceitos elaborados pelos filósofos para ajudar os estudantes a compreendê-los de forma filosófica e para que entendam como os filósofos resolveram suas questões, indicando assim um fazer filosófico. Como em uma peça teatral, há sempre o movimento da vida que inicia o movimento no pensamento.

Discorrendo sobre sua prática no Liceu, em Orléans (1952 a 1955), Dosse (2010) menciona a estratégia de Deleuze de começar as aulas sempre relatando um acontecimento engraçado ocorrido (inventado?), no caminho de Paris, onde residia, até Orléans, pelo qual sempre acontecia algo cômico. Um de seus alunos, Alain Roger, assim descreve uma dessas aulas:

Levaram minha valise... Um engano... uma terrível confusão... no ônibus de Aubrais... Então, imaginem vocês, abro minha valise no hotel, $e$ o que é que eu vejo? Colgate, Palmolive, essas coisas... Um representante comercial... Lembro dele, sem dúvida... um senhor gordo... Um belga, sem dúvida. Todos gordos numas casinhas pequenas... Como vocês querem que eu dê aula com dentrifícios e cremes de barbear? Por outro lado, o senhor gordo... quando ele abrir minha valise... diante de todos os seus clientes... o que é que

Número 34: nov. 2020 - abril 2021 
ele vai lhes mostrar? A Crítica da Razão Pura... e minha aula sobre o transcendental... nada disso é vendável... Ele vai perder seu ganhapão, eu me sinto mal... Enfim, vou pelo menos tentar lhes dar aula [...].

Após esse preâmbulo, a aula pode começar. Deleuze tira um papel do bolso, desdobra-o lentamente e fica segurando na mão, sem jamais consultar. Dá a impressão de improvisação, mas se sabe, e voltaremos a isso, do cuidado meticuloso com que preparava suas aulas. Dando a impressão de estar no mesmo nível que seu público, de não ter preparado nada e de ser pego desprevenido, ele finge estar perturbado diante das questões que coloca a si em voz alta: 'Ah! O transcendental, o que é isso? Kant diz claramente que são as condições de possibilidade... Mas, por que chamar isso de transcendental?... Não sei, não sei mesmo'. Pouco a pouco a decantação se opera, as linhas do problema se desenham, as articulações tornam luminoso o discurso: 'Ele procedia por repetições sob ângulos diferentes, praticando uma espécie de perfuração em espiral'. Assim como em Amiens, Espinosa é o que mais se discute em suas aulas em Orléans: 'Ele comentou o início da Ética durante três ou quatro meses'. (DOSSE, 2010, p. 92. Grifos nossos).

É interessante observar nesse relato alguns pontos importantes: 1) a abordagem de Deleuze em começar a aula chamando a atenção dos alunos por meio de uma história engraçada (um momento alegre, uma comédia!) e, logo em seguida, aproveitando a situação da história, começar sua aula introduzindo o tema; 2) colocar-se perante os alunos com simplicidade, sem arrogância, teatralizando um possível problema de como dar a aula sem o material, já que o havia perdido durante a viagem, simulando uma postura teatral de desconhecimento da questão que vai trabalhar (que foi, no entanto, exaustivamente preparada anteriormente); 3) trabalhar a questão ou o problema em análise de diferentes formas para facilitar $e$ proporcionar aos alunos melhor compreensão; 4) por último, a postura de Deleuze de dedicar o tempo necessário para trabalhar uma só questão: o início de uma obra, durante um tempo bastante longo para os padrões de nossa prática usual. A nosso ver, isso revela, por parte de Deleuze, uma preocupação em conduzir os alunos a compreenderem o que estão lendo e cada vez mais estimulá-los a aprofundarem a questão, problematizando isso. O tempo necessário é o tempo da compreensão e não o tempo dos conteúdos a serem vencidos e estudados.

Uma aula é um cubo, ou seja, um espaçotempo. Muitas coisas acontecem numa aula. Nunca gostei de conferências porque se trata de um espaçotempo pequeno demais. Uma aula é algo que se estende de uma semana a outra. É um espaço e uma temporalidade muito especiais. Há uma sequência. (DELEUZE, 2008).

Quanto à prática em sala de aula, que também podemos entender como um teatro filosófico do ensino, Deleuze adotava o estilo dito aula magistral ou concerto musical em que o professor fala e, como em uma peça musical, em um teatro musical, o ouvinte vai percebendo o movimento do seu pensamento se desenvolvendo, criando seus efeitos. Nesse movimento, cada estudante aproveita o que lhe convém e interessa, alguém será despertado para algo que lhe interessa, ha- 
vendo emoção e inteligência envolvidas nesse processo. Assim, em uma aula, cada um pegava o que lhe interessava ou precisava $e$ podia dispensar tudo o mais (DELEUZE, 2008).

Como poderíamos caracterizar uma aula, a partir de Deleuze? Primeiro, ela é um curso, tem uma longa duração, um constante encontro com um determinado tema ou problema; segundo, esse caminho, esse curso é sobre aquilo que se busca. A aula, então, não é uma repetição, mas uma construção, um laboratório de pesquisa sobre algo que se busca. É um momento de levantar novas questões ainda não exploradas, que passaram despercebidas ou mesmo foram mal compreendidas. As questões que precisam ser colocadas numa aula são sempre pessoais, há necessidade de uma personagem que busca uma resposta, e cabe a cada um elaborar sua questão, do contrário não haverá interesse, não haverá o que dizer (DELEUZE; PARNET, 1998).

Podemos entender que a aula é um lugar de paciência, de desaceleração, de lentidão. Há necessidade de abertura e respeito ao tempo de cada um nesse processo. Ensinar filosofia compreende, para Deleuze, uma longa preparação, um ensaio que não se constitui em um método de controle, mas em uma prática de movimentos que produzem encontros e emitem signos. Há, em Deleuze, toda uma preocupação com o encontro com os alunos. A sua prática filosófica é um verdadeiro teatro filosófico: o movimento do conceito, a partir de um plano de imanência, gestado por personagens conceituais, atores desse drama do pensamento. Assim, o processo de pensamento se dá sempre por uma irrupção da experiência, no encontro de corpos, na produção de efeitos e na interpretação desses efeitos produzidos pelo sentido constituído.

\section{Considerações finais}

Criar conceitos é tarefa da filosofia como busca do sentido do acontecimento, encontro entre corpos, cujo efeito é a produção de afectos que constituem signos provindos desse encontro. Assim, não é o sujeito o ponto de partida do pensamento, mas esse caos exterior que vem ao encontro do sujeito no acontecimento, engendrando os problemas provindos desses signos emitidos. Problemas que em sua formulação fixam um plano de imanência a partir dos quais os conceitos filosóficos podem ser criados. $\mathrm{O}$ acontecimento é sempre a expressão da singularidade do espaçotempo, repetição da infinita diferença que cada encontro traz consigo. Teatro da repetição da diferença, teatro do caráter sempre novo dos conceitos.

A aprendizagem filosófica como criação de conceitos precisa ser considerada em face da atitude diante do acontecimento. Viu-se com Deleuze (2018, p. 31) que a "aprendizagem não se faz na relação da representação com a ação (como reprodução do mesmo), mas na relação do signo com a resposta (como encontro com o outro)". Aprender é constituir esse espaço de encontro com os signos, onde se podem construir os problemas filosóficos, sejam eles mais práticos sejam especulativos, é o ato subjetivo de uma singularidade operado em face da objetividade do problema. A aprendizagem filosófica não é da ordem do saber, é da ordem do teatro, da colocação em cena de um problema conceitual que emerge do plano de imanência de uma vida. 
Assim, aprender um conceito filosófico não é o movimento intermediário entre o não saber $e$ o saber que visa a um resultado composto pela generalidade do conceito $e$ pela posse de uma regra de ação; é antes o movimento de dramatização de um personagem conceitual em um "teatro de problemas e questões sempre abertos, levando consigo o espectador, a cena e os personagens no movimento real de uma aprendizagem". Há uma ênfase no movimento do pensamento e não no resultado do saber, movimento do fora que produz seus efeitos em uma percepção, em uma sensibilidade, em um pensamento novo que não deve ser avaliado pelos resultados que obtêm, mas pela qualidade de seus cursos e pela potência de sua continuação, os conceitos são intensidades. A qualidade da aprendizagem filosófica se mede, assim, pelo movimento de criação de conceitos, entendido como um novo pensar que passa também por novas maneiras de ver e ouvir e novas maneiras de sentir.

Por fim, o ensinar filosofia também se desloca nesta nova imagem do pensamento. Ensinar filosofia passa a ser da ordem da colocação em cena de muitos encontros possíveis do aprendiz com a cultura, ativado por meio dos signos emitidos nesses encontros, de modo a criar as condições favoráveis para o estabelecimento do problema filosófico como resposta em direção ao trabalho infinito de criação de conceitos, já que, como cena dramática, compreende em si a singularidade, como os atores que, repetindo cada vez de novo a cena, produzem na diferença algo efetivamente novo.

\section{Referências}

ARAYA, Adán Salinas. Filosofía teatral: lecturas posibles de Deleuze. Hermenéutica intercultural, n. 32, 2019.

BIANCO, Giuseppe. Gilles Deleuze Educador: sobre a pedagogia do conceito. Educação $e$ realidade, v. 27, n. 2, 2003.

BRÉHIER, Émile. A teoria dos incorporais no estoicismo antigo. Belo Horizonte: Autêntica, 2012.

DELEUZE, Gilles. O abecedário de Gilles Deleuze. Disponível em: http://www.bibliotecanomade.com/2008/03/arquivo-para-download-o-abecedrio-de.html. Acesso em: 20 mai. 2019.

DELEUZE, Gilles. Curso sobre Spinoza. Paris, 1978 [Aula do dia 24/01/1978]. Disponível em: https://www.webdeleuze.com/textes/12. Acesso em: 27 jul. 2019.

DELEUZE, Gilles. Diferença e repetição. São Paulo: Paz e Terra, 2018.

DELEUZE, Gilles. Espinosa e o problema da expressão. São Paulo: Ed. 34, 2017. 
DELEUZE, Gilles. Lógica do sentido. 5 ed. São Paulo: Perspectiva, 2015.

DELEUZE, Gilles; GUATTARI, Félix. O que é filosofia? São Paulo: Editora 34, 2010.

DELEUZE, Gilles. Proust e os signos. 2. ed. Rio de Janeiro: Forense Universitária, 2003.

DELEUZE, Gilles; PARNET, Claire. Diálogos. São Paulo: Escuta, 1998.

DELEUZE, Gilles. Conversaçôes: 1972-1990. Rio de Janeiro: Ed. 34, 1992.

DOSSE, François. Gilles Deleuze e Félix Guattari: biografia cruzada. Porto Alegre: Artmed, 2010.

FOUCAULT, Michel. Theatrum Philosophicum In:

. Ditos e escritos. Vol. II: arqueologia das ciências e história dos sistemas de pensamento. Rio de Janeiro: Forense Universitária, 2005, p. 230-254.

GALLO, Sílvio. Metodologia do ensino de filosofia: uma didática para o ensino médio. Campinas: Papirus, 2012.

LA SALVIA, André Luis. A extração de problemas de uma pedagogia do conceito. Tese (Doutorado em Filosofia) - Universidade Estadual de Campinas, Instituto de filosofia e ciências humanas, Campinas, 2015.

LA SALVIA, André Luis. Deleuze e Guattari: uma aula sobre o que se busca. In: VELASCO, Patrícia Del Nero (Org.). Ensino de - qual? - filosofia: ensaios a contrapelo. Marília: Oficina Universitária; São Paulo: Cultura Acadêmica, 2019.

MACEDO, William Gustavo da Silva; CARVALHO, Flávio José de. Investigação acerca da pedagogia do conceito e sua aplicabilidade no ensino de filosofia no ensino médio. Problemata. v. 9, n. 3, p. 26-36, 2018.

VASCONCELLOS, Jorge. Teatro e filosofia em Gilles Deleuze. Artefilosofia, Ouro Preto, n. 9, p. 101-108, out. 2010.

Recebido em: $30 / 05 / 2020$

Aprovado em: 22/10/2020 